\title{
RADIATIVE TRANSFER MODEL SIMULATIONS TO DETERMINE THE NIGHT TIME FOG DETECTION THRESHOLD
}

\author{
Sheetabh Gaurav ${ }^{1, *}$, Pooja Jindal ${ }^{1}$ \\ ${ }^{1}$ Indian Institute of Remote Sensing, ISRO, Dehradun, India - sheetabhgaurav@gmail.com, pooja_j@iirs.gov.in
}

Commission V, SS: Atmosphere, Ocean, Weather and Climate

KEY WORDS: Fog detection, Radiative Transfer Model, SBDART, Indo-Gangetic plain, Brightness temperature difference threshold, Middle Infrared, Thermal Infrared

\begin{abstract}
:
Every winter the Indo-Gangetic plains (IGP) of northern India are severely impacted both socially and economically by fog. For night time fog detection, visible imagery cannot be used. Also, as emissions from ground and fog is almost similar in thermal infrared (TIR, $10.8 \mu \mathrm{m}$ ) channel, TIR channel cannot help in identifying fog. However, emission in middle infrared (MIR, $3.9 \mu \mathrm{m})$ channel is less than emission in TIR channel over foggy area. Therefore, brightness temperature difference (BTD) between TIR and MIR is positive during night time over fog area. This BTD technique cannot be directly used during day time as MIR channel is contaminated by solar radiations. In the present work, a spectral sensitivity analysis study has been done for these two spectral channels using radiative transfer model (RTM) simulations to determine a threshold BTD for night time fog detection. SBDART (Santa Barbara DISORT Radiative Transfer) model was used for this study to simulate brightness temperatures (BT). The RTM simulations of BT of the two spectral channels was carried out for different fog microphysical characteristics like fog optical depth (FOD) and fog droplet size (Re). The fog episode of January 2018 over IGP was studied by applying threshold BTD obtained from simulation results for INSAT-3D data. A threshold BTD value $>5 \mathrm{~K}$ detected night time fog over IGP with good accuracy. The threshold BTD obtained from satellite image is compared with different cases established from simulation result which gave idea about microphysical properties of fog over IGP during winter seasons.
\end{abstract}

\section{INTRODUCTION}

Fog is a low level cloud with cloud base at or very close to the Earth's surface. It is made up of small water droplets or ice crystals suspended in air, influenced by water bodies close-by, wind conditions and topography. It is formed by the radiation cooling process when the air containing water vapour is cooled below its saturation or dew point. Also the presence of air pollutants and aerosols attribute to the formation of fog. It is one of the important meteorological environmental phenomena which affect the human life by disrupting the road and air traffic as it reduces the horizontal visibility to less than 1000 meters (1 $\mathrm{km})$.

Fog formation takes place mostly in the lower layer of troposphere where aerosols and gases are found in abundance. In terms of appearance and structure, it is very same as clouds. The most evident difference between the two is the method and place of formation. When air rises and cools adiabatically, the cloud is formed. On the other hand, fog is formed as a result of cooling or saturation of air by addition of water vapour (evaporation fog) (Kidder \& Wu, 1984) or through radiation cooling. At a given pressure and temperature, if the air contains the maximum possible amount of water vapour, it is said to be saturated air. When air reaches the saturation level, fog is formed by the condensation of water vapour on condensation nuclei. Condensation nuclei are the surfaces present in natural air on which water vapour can condense (for example, smoke, dust, salt from ocean, etc.).

\footnotetext{
* Corresponding author
}

During the winter season in India (November-February), dense and prolonged fog develops over the Indo-Gangetic plains (IGP) due to favourable meteorological conditions for fog formation (Choudhury et al., 2007). The fog over the IGP forms mostly in association with the western disturbances. Western disturbances are the mid latitude storms which originate over Mediterranean Sea and western part of Asia and move to India. These storms are upper tropospheric systems of high and low pressure which move in eastward direction. Also various physical and chemical properties of aerosols (like size and chemical composition) have a significant impact on the occurrence of fog (Badarinath et al., 2007). Aerosol content over the IGP is increasing at an alarming rate with the growing population, industrialization and urbanization which have a significant impact on weather and climatic conditions (Badarinath et al., 2007) and hence fog formation.

The information provided by weather stations about the fog episodes is based on point observation which is insufficient to determine the true extent of fog. Also during night time, these observation stations have limited capabilities. As a result, in order to continuously monitor the spatial and temporal extent of fog over a large area such as IGP, satellite-based observations are needed due to its higher spatial and temporal coverage. Brightness is one of the essential characteristics of the satellite images. It depends upon the albedo of the underlying surface in visible imagery. Highly reflecting surfaces such as clouds and snow appear white as compared to land and sea which appear darker. Fog clouds have higher albedo as compared to land (apart from snow). As a result, in visible channel (around 0.67 $\mu \mathrm{m})$, fog area appears brighter than the ground. Also the texture of fog is smoother as compared to other clouds. However, 
visible channel is not available during night time. In TIR channel (around $10.8 \mu \mathrm{m}$ ), it is difficult to differentiate the earth's surface and fog. This is due to the fact that the formation of fog takes place very close to the earth's surface, therefore temperature difference between the fog and earth's surface is less. The lower thermal sensitivity of TIR channel is not significant to see fog and earth's surface separately. Hence, only TIR channel cannot provide sufficient information for fog detection during night time. For night time fog detection, the brightness temperature difference between TIR and MIR channels is considered. The emissivity of fog in MIR channel is about 0.8-0.9 and in TIR channel it is almost 1 (Ellrod, 1995; Lee et al., 2011). Therefore TIR minus MIR is greater than $0 \mathrm{~K}$ over foggy region. However during daytime, the MIR channel (around $3.9 \mu \mathrm{m}$ ) has both reflective and emissive components as the signal gets contaminated with solar radiation (Kidder $\& \mathrm{Wu}$, 1984). Hence the difference between TIR and MIR cannot be used during day time for fog detection.

India has launched a series of geostationary satellites called INSAT (Indian National Satellite) which carries both meteorological and communication payloads. INSAT-3D, launched on 26 July, 2013, is designed for meteorological observations, land and ocean surface monitoring, weather forecasting and disaster warning. It carries four payloads -6 channel multispectral imager, 19 channel Sounder, Data Relay Transponder (DRT) and Search and Rescue Transponder (SART). Imager and Sounder are two meteorological payloads.

A bi-spectral remote sensing technique based on the BTD between the two channels - TIR and MIR is presented in the present study. A BTD threshold was determined using RTM simulations for the detection of night time fog. RTMs are atmospheric models which calculate radiative transfer of the electromagnetic radiation through the Earth's atmosphere. The whole study is split into two parts. In the first part, the output radiance for the two spectral channels at top of the atmosphere is determined using RTM simulations. BT is derived from the output radiance for TIR and MIR channel. Then the BTD threshold for fog detection is determined. The second part involves the study of fog episode of $2^{\text {nd }}$ to $5^{\text {th }}$ January 2018 over Indian region, mostly the IGP using INSAT-3D satellite data.

\section{RELATED WORK}

BTD thresholding technique has been used in various studies to study fog. A bi-spectral BTD thresholding technique was conducted to study the fog episodes of 2009 and 2010 over the Northern India using MODIS data (Chaurasia et al., 2011). The study gives us an idea about the association of prolonged fog episode of 2010 with western disturbances over the northern plains of India. Similar kind of study based on BTD threshold technique was done to develop an algorithm on temporally continuous fog detection (Lee et al., 2011). The study included one of the major problem associated with algorithms using satellite imagery to detect fog, i.e. temporal discontinuities, especially during dusk and dawn. Since this study focused on temporally continuous fog detection algorithm, a dynamic threshold was formulated as a function of solar zenith angle to detect fog during day time also. In another study, BTD threshold was reduced to $2.5^{\circ} \mathrm{C}$ to study 2010-2011 fog episodes in IGP using satellite data (Ahmed, Dey, \& Mohan, 2015). The method using $2.5^{\circ} \mathrm{C}$ BTD threshold was validated against ground-based observations which gave an accuracy of $83.9 \%$. According to this study, this accuracy goes up to $88.3 \%$ if the threshold is further reduced to $1.5^{\circ} \mathrm{C}$. Also the study investigated the connection of fog with the aerosols.

Srivastava et al. (2016) studied fog over Indo-Gangetic plain during winter seasons along with its trend and spatio-temporal variability. This study gave some interesting statistics about fog frequency over IGP during December and January months in last 4-5 decades (1971-2015). It showed that during peak winter months, i.e. December and January, the frequency of fog has gone up by $118.4 \%$. The most number of foggy days have been in the central part of IGP, i.e. $66.29 \%$ which is followed by the western part of IGP with $41.94 \%$ fog days. The study indicated that the increasing trend of fog is mainly due to anthropogenic aerosols caused due to burning of coal, wood, paraffin, etc. Also it suggested that the rapid industrialization and increased use of vehicle is also a major factor contributing release of aerosols.

\section{STUDY AREA AND DATA USED}

\subsection{Study Area}

The study region was the Indo Gangetic plain (IGP) of India shown in Figure 1. The IGP comprises of north-central section of the Indian subcontinent separating the peninsula from the Himalayas. The IGP of India runs parallel to the Himalayas, from Gujarat, Rajasthan and Punjab in the west to Assam in the east. It stretches 2400 kilometers from west to east, encompassing an area of $700,000 \mathrm{~km}^{2}$. It is the most densely populated part of India.

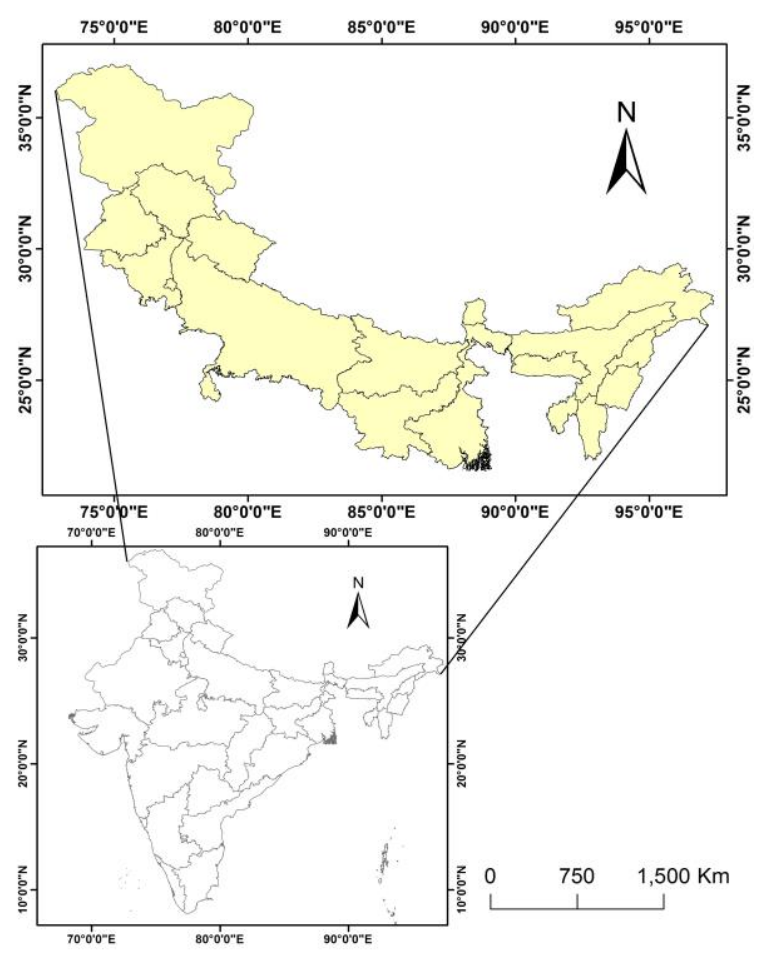

Figure 1. Study Area - Indo Gangetic Plain of India

\subsection{Data Used}

For the second part of the study to determine BTD threshold from the satellite data, INSAT-3D imager products were used. For radiance values, Level-1B product was used and Level-2C product was used for the fog map. The INSAT-3D imager is one 
of the two meteorological payloads, which works in the spectral region of visible to infrared (0.55 to $12.5 \mu \mathrm{m})$. From a geostationary altitude, it provides images of the earth in 6 channels as depicted in Table 1.

\begin{tabular}{|c|c|c|c|}
\hline $\begin{array}{c}\text { Spectral } \\
\text { Channels }\end{array}$ & $\begin{array}{c}\text { pectral Range } \\
(\boldsymbol{\mu m})\end{array}$ & Resolution (km) & $\begin{array}{c}\text { Quantization } \\
\text { bits }\end{array}$ \\
\hline VIS & $0.55-0.75$ & 1 & 10 \\
\hline SWIR & $1.55-1.70$ & 1 & 10 \\
\hline MIR & $3.80-4.00$ & 4 & 10 \\
\hline WV & $6.50-7.10$ & 8 & 10 \\
\hline TIR 1 & $10.3-11.3$ & 4 & 10 \\
\hline TIR 2 & $11.5-12.5$ & 4 & 10 \\
\hline
\end{tabular}

Table 1. Payload specification for INSAT-3D imager

\section{METHODOLOGY}

The entire study is split into two parts. The first part involves determination of threshold BTD by spectral sensitivity analysis for the two channels - TIR $(10.8 \mu \mathrm{m})$ and MIR $(3.9 \mu \mathrm{m})$ which was carried out using RTM simulations. In the second part, INSAT-3D satellite data is used to study the fog episode of January 2018 over IGP. Figure 2 represents the flowchart of the entire study.

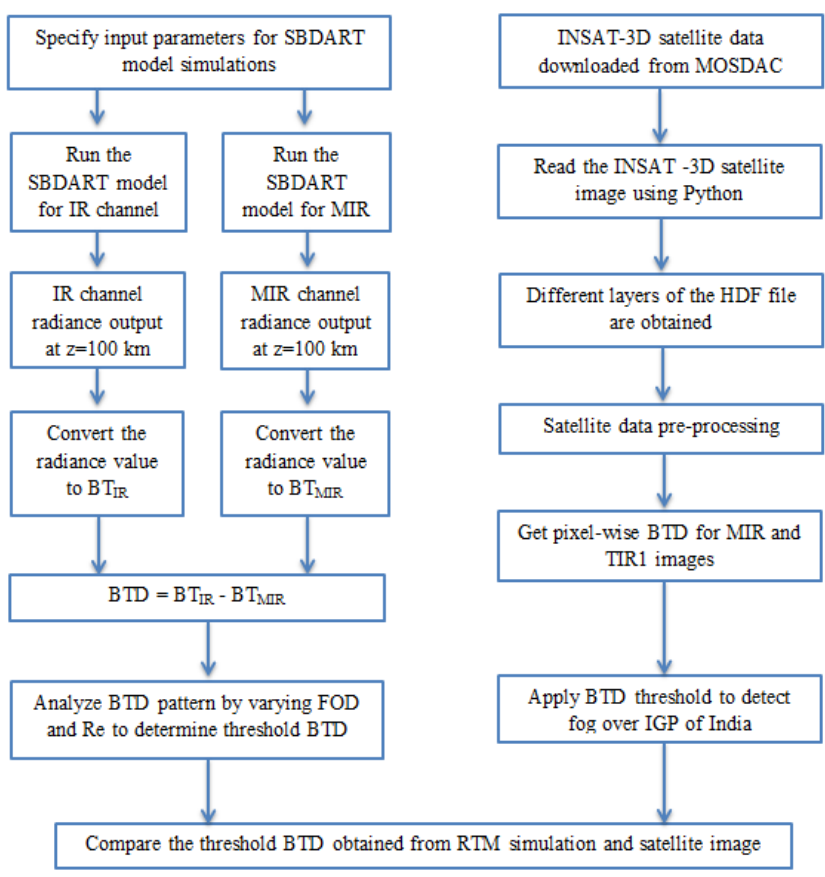

Figure 2. Flowchart depicting study methodology

\subsection{Radiative Transfer Model (RTM) simulation to determine the night time fog threshold}

The first part of the study deals with the spectral sensitivity analysis for the two spectral channels - TIR $(10.8 \mu \mathrm{m})$ and MIR (3.9 $\mu \mathrm{m})$ using RTM simulations. The main purpose of the spectral sensitivity analysis for the two channels was to determine a threshold BTD for night time fog detection. The RTM simulations were conducted using the SBDART (Santa Barbara DISORT Atmospheric Radiative Transfer) model. This model was written in FORTRAN language for various radiative transfer studies and their analysis in the earth's atmosphere (Ricchiazzi et al., 1983).

To run the RTM simulations for fog, the most important parameters considered were fog optical depth (FOD) and fog droplet effective radius (Re). In present study, the fog cloud base was considered to be approximately $1 \mathrm{~m}$ above the ground and fog cloud layer height ranges from $1 \mathrm{~m}$ to $50 \mathrm{~m}$ above the ground. The FOD ranges up to 30 from different experimental observations (Bendix, 2002; Lu \& Shengjie, 2009). Here in this study, the FOD ranges from 0 (no fog case) to 16 and Re varies from $2 \mu \mathrm{m}$ to a maximum of $20 \mu \mathrm{m}$ (case of marine fog). For the simulation of model, atmospheric profile of the tropical model atmosphere has been considered. A spectrally uniform surface albedo was considered for RTM simulations. Since these simulations were carried out to detect night time fog, solar zenith angle was kept greater than $90^{\circ}$ to turn off the solar input. Using these parameters, the SBDART model was run for $\lambda=3.9$ $\mu \mathrm{m}$ (MIR) and $\lambda=10.8 \mu \mathrm{m}$ (TIR) wavelengths. Table 2 gives an overview of the input parameters considered to run RTM simulations using SBDART model.

Once the input parameters for RTM simulation were set, the SBDART model was run using Unix shell scripts for wavelengths $\lambda=3.9 \mu \mathrm{m}$ (MIR) and $\lambda=10.8 \mu \mathrm{m}$ (TIR). On successful run of the scripts, radiance output was obtained for $\mathrm{z}$ $=100 \mathrm{~km}$ at Top of the Atmosphere (TOA) for both MIR and TIR channels. The radiance outputs were generated for each FOD $(0,2,4,8,12,16)$ and $\operatorname{Re}(2,4,8,12,16,20 \mu \mathrm{m})$. The radiance outputs obtained were then converted to brightness temperature using Planck's radiation law equation.

\begin{tabular}{|c|l|l|l|}
\hline $\begin{array}{r}\text { Sl. } \\
\text { No. }\end{array}$ & Parameter & Description & Values \\
\hline 1. & Wavelength & $\begin{array}{l}\text { Central wavelength for MIR } \\
\text { and IR channel. }\end{array}$ & MIR: $\lambda=3.9 \mu \mathrm{m}$ \\
TIR: $\lambda=10.8 \mu \mathrm{m}$
\end{tabular}

Table 2. Input parameters configuration for SBDART model 
The spectral characteristics of thermal emission from a body at temperature $\mathrm{T}$ deg $\mathrm{K}$ are described by Planck's radiation law given by Equation 1 .

$$
\mathrm{B}_{\lambda}(\mathrm{T})=\left(\mathrm{C}_{1} \lambda^{-5}\right) /\left(\mathrm{e}^{\mathrm{C}_{2} / \lambda \mathrm{T}}-1\right)
$$

where

$$
\begin{aligned}
& \mathrm{B}_{\lambda}(\mathrm{T})=\text { spectral emittance at temperature } \mathrm{T} \\
& \lambda=\text { wavelength in metres } \\
& \mathrm{C}_{1}=3.74 \times 10^{-16} \mathrm{Wm}^{-2} \\
& \mathrm{C}_{2}=1.44 \times 10^{-2} \mathrm{deg} \mathrm{K}
\end{aligned}
$$

Brightness temperature (BT) for the two spectral channels is calculated from radiance outputs using the Planck's equation, see Equation 2.

$$
\mathrm{BT}=\mathrm{C}_{2} / \lambda *\left[\ln \left(\left(\mathrm{C}_{1} \lambda^{-5} / \mathrm{B}_{\lambda}\right)+1\right)\right]
$$

Putting the values of output radiance $\left(\mathrm{B}_{\lambda}\right)$ in the Equation 2, we obtain BT values for IR (BTIR) and MIR (BTMIR). Then, the brightness temperature difference (BTD) can be calculated as:

$$
\mathrm{BTD}=\mathrm{BT}_{\mathrm{IR}}-\mathrm{BT}_{\mathrm{MIR}}
$$

The BTD obtained is analysed for different combinations of FOD and Re to determine threshold BTD for night time fog detection.

\subsection{Brightness Temperature Difference threshold for fog detection using INSAT-3D satellite data over IGP}

For this part of study, INSAT-3D imager Level-1B Standard Product was used. This dataset provides images of the earth disk in six different wavelength regions - visible, shortwave infrared, middle infrared, water vapour and two in thermal infrared. It provides information for generating radiance, brightness temperature, geo-locations in terms of latitude and longitude. From the INSAT-3D imager product pixel-wise BT was obtained for both TIR 1 and MIR channel. Once pixel-wise BT was obtained for both channels and for each pixel, BTD was calculated by taking the difference of BTs for TIR 1 and MIR channel as per Equation 3

From the satellite image, the fog pixels were extracted over Indian region IGP by applying different threshold BTDs determined from the simulation result. The time period for the study is from $2^{\text {nd }}$ to $5^{\text {th }}$ January 2018 (2100 UTC/0230 IST). INSAT-3D imager Level-2C fog product was used to compare the fog detected by applying present threshold BTD method with operational fog product.

\section{RESULTS AND DISCUSSION}

\subsection{Brightness temperature difference threshold using Radiative Transfer Model simulations}

The fog optical depth (FOD) and fog droplet effective radius (Re) were the two fog cloud microphysical parameters considered during the RTM simulations using SBDART model. The variation of BT was observed with each of these parameters for the two spectral channels - TIR $(10.8 \mu \mathrm{m})$ and MIR (3.9 $\mu \mathrm{m})$. Table 3 shows the SBDART simulation results in terms of BT for these channels and corresponding BTD for different FOD and Re.
5.1.1 Variation of BT (K) with fog optical depth: For this study, FOD varies from 0 (no fog case) to 16 . Figure 3 illustrates the variation of BT (K) with FOD for $\operatorname{Re}=4 \mu \mathrm{m}$ in TIR and MIR channels respectively. The variation of BTD between the two channels with FOD is also depicted in the plot.

Following observations are made as the result of RTM simulations:

- $\quad$ For an average fog droplet size of $4 \mu \mathrm{m}$, the drop in BT is much more rapid in MIR channel as compared to TIR channel. In TIR channel, only a slight decrease in BT is observed as the fog cloud optical depth increases. This pattern is evident from Table 3 .

- The BTD values between the two spectral channels are higher for optically dense fog and very low for optically thin fog which can be seen in Table 3. From this observation, it can be concluded that it is difficult to detect optically thin fog.

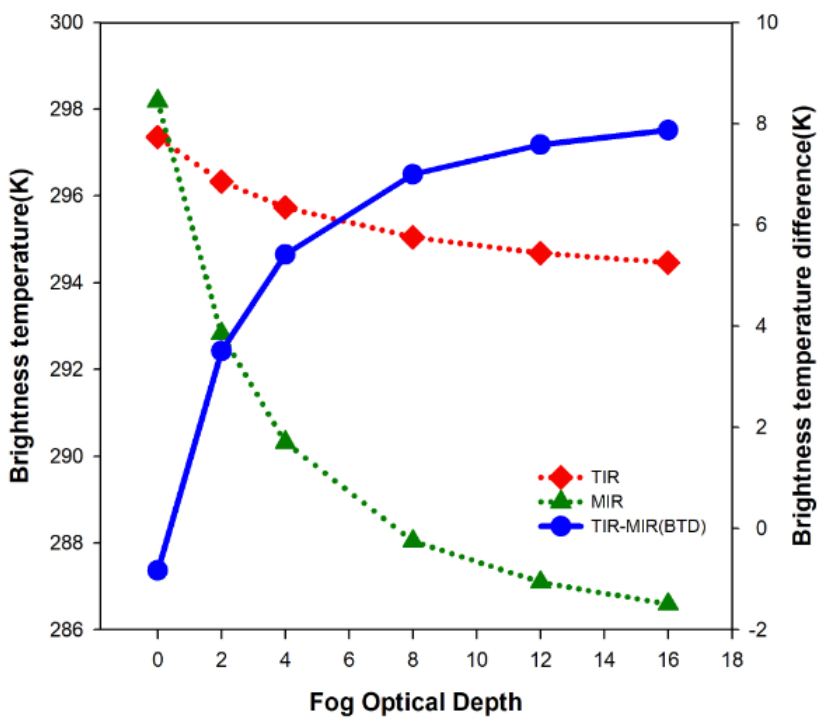

Figure 3. BT $(\mathrm{K})$ and BTD $(\mathrm{K})$ variation with FOD

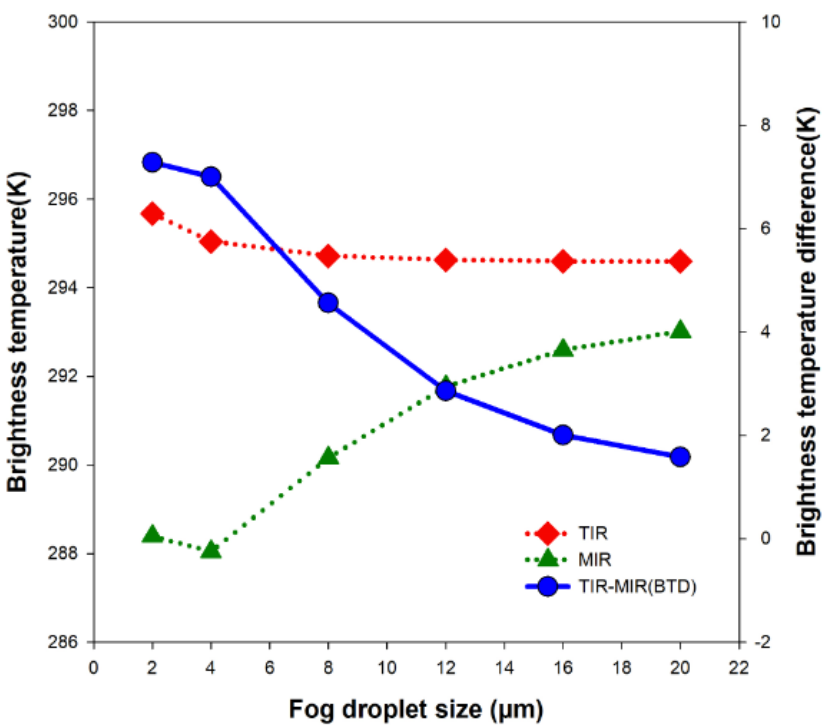

Figure 4. BT (K) and BTD (K) variation with Re 
5.1.2 Variation of BT (K) with fog droplet size (Re): For this study, Re varies from $2 \mu \mathrm{m}$ to a maximum of $20 \mu \mathrm{m}$ (case of marine fog). Figure 4 illustrates the variation of BT (K) with Re in TIR and MIR channels respectively assuming the FOD to be 8 . The plot also depicts the variation of BTD between the two channels with Re.

Following observations are made as the result of RTM simulations which are depicted in Table 3:
- With an increase in Re, BT decreases slightly for TIR channel. After $\operatorname{Re}=6 \mu \mathrm{m}$, the BT follows almost constant trend.

- For MIR channel, BT follows a slight decreasing trend until $\mathrm{Re}=4 \mu \mathrm{m}$, after that it increases rapidly with increasing Re.

- For small Re, the BTD between the two channels are on a higher side. For an average droplet size of 4$8 \mu \mathrm{m}$, BTD is around $\sim 4 \mathrm{~K}$. As the Re increases further, the BTD decreases rapidly.

\begin{tabular}{|c|c|c|c|c|c|c|c|c|c|c|c|c|c|c|c|c|c|c|c|}
\hline & \multicolumn{19}{|c|}{ Fog droplet size (in $\mu \mathrm{m}$ ) } \\
\hline \multirow{8}{*}{$\begin{array}{c}\text { Fog } \\
\text { optical } \\
\text { depth }\end{array}$} & & \multicolumn{3}{|c|}{2} & \multicolumn{3}{|c|}{4} & \multicolumn{3}{|c|}{8} & \multicolumn{3}{|c|}{12} & \multicolumn{3}{|c|}{16} & \multicolumn{3}{|c|}{20} \\
\hline & & TIR & MIR & BTD & TIR & MIR & BTD & TIR & MIR & BTD & TIR & MIR & BTD & TIR & MIR & BTD & TIR & MIR & BTD \\
\hline & 0 & 297 & 298 & -0.8 & 297 & 298 & -0.8 & 297 & 298 & -0.8 & 297 & 298 & -0.8 & 297 & 298 & -0.8 & 297 & 298 & -0.83 \\
\hline & 2 & 297 & 294 & 2.87 & 296 & 293 & 3.51 & 296 & 294 & 2.46 & 296 & 294 & 1.38 & 296 & 295 & 0.8 & 296 & 295 & 0.51 \\
\hline & 4 & 296 & 291 & 4.93 & 296 & 290 & 5.41 & 295 & 292 & 3.64 & 295 & 293 & 2.15 & 295 & 294 & 1.39 & 295 & 294 & 1.01 \\
\hline & 8 & 296 & 288 & 7.28 & 295 & 288 & 7 & 295 & 290 & 4.56 & 295 & 292 & 2.86 & 295 & 293 & 2.01 & 295 & 293 & 1.58 \\
\hline & 12 & 295 & 287 & 8.42 & 295 & 287 & 7.58 & 294 & 290 & 4.93 & 294 & 291 & 3.21 & 294 & 292 & 2.34 & 294 & 292 & 1.9 \\
\hline & 16 & 295 & 286 & 9.02 & 294 & 287 & 7.87 & 294 & 289 & 5.15 & 294 & 291 & 3.42 & 294 & 292 & 2.54 & 294 & 292 & 2.08 \\
\hline
\end{tabular}

Table 3. SBDART simulation result in terms of BT for different fog microphysical parameters
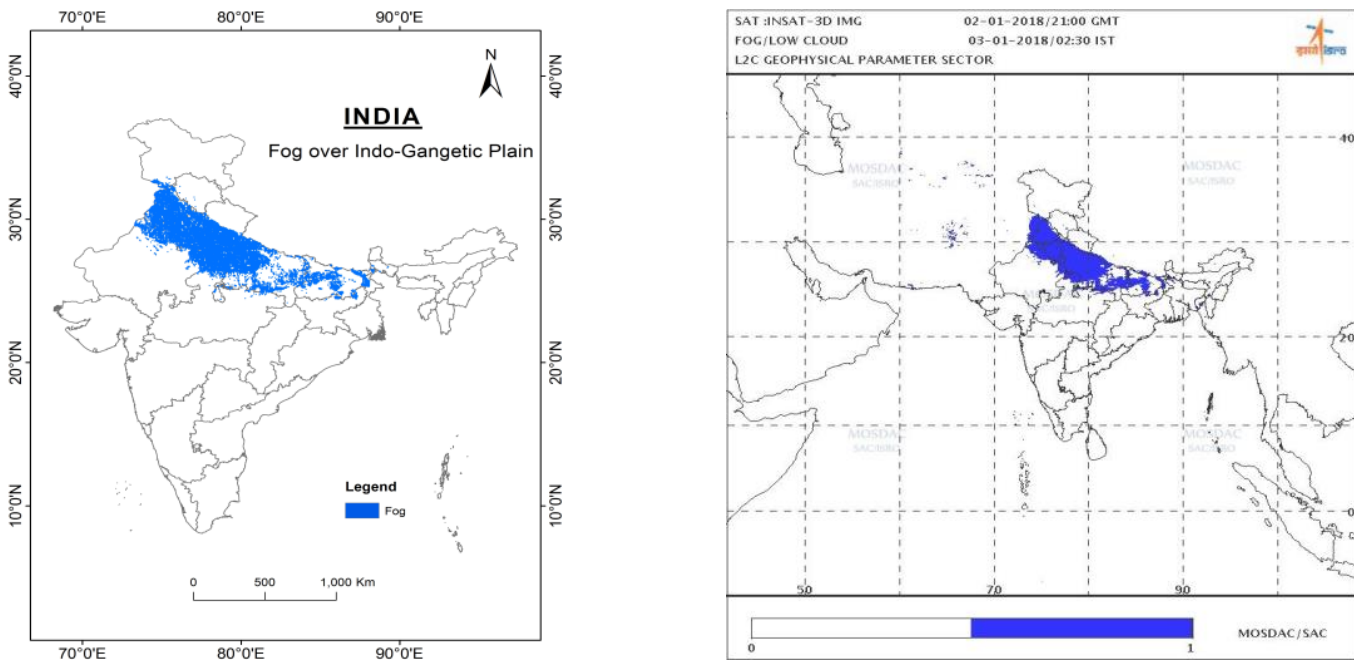

(a)
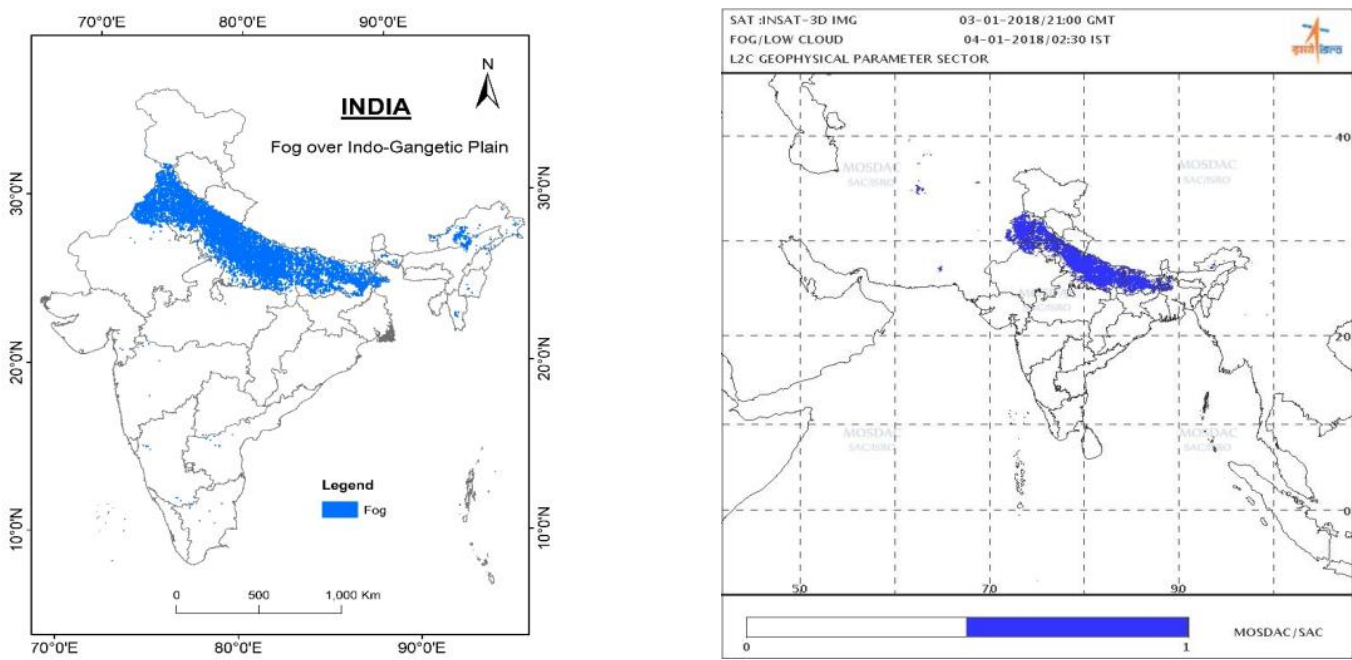

(b) 

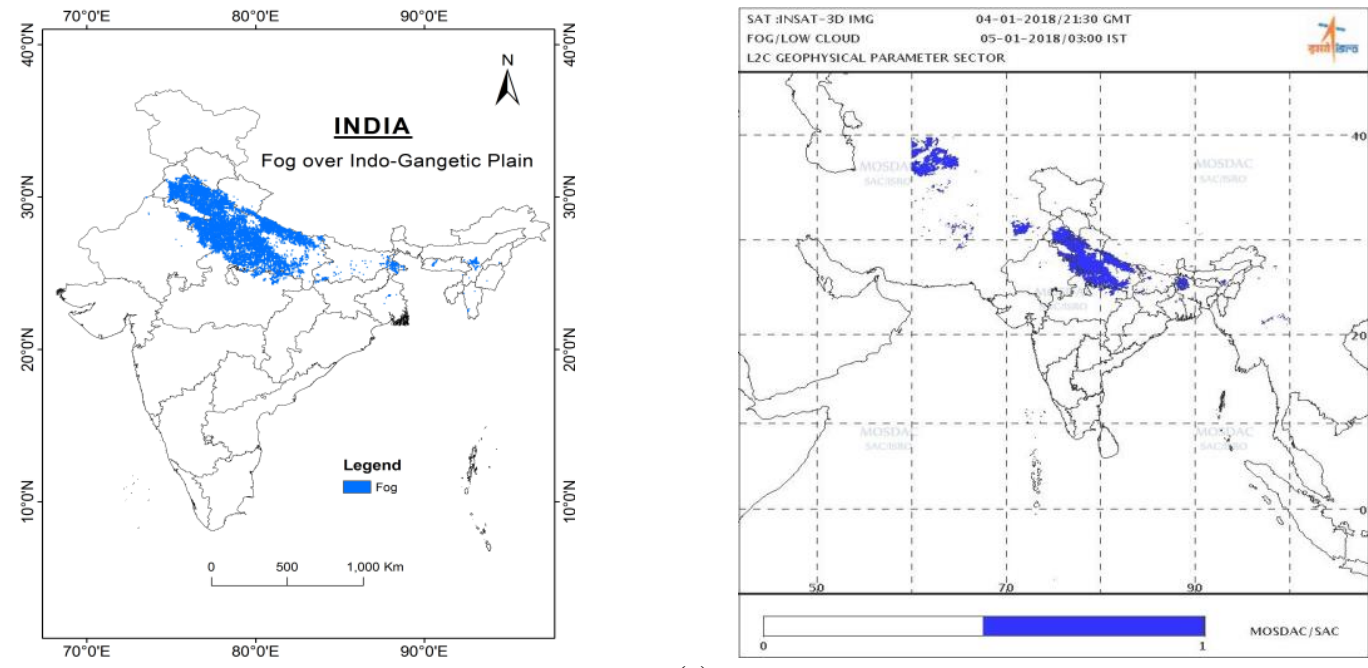

(c)
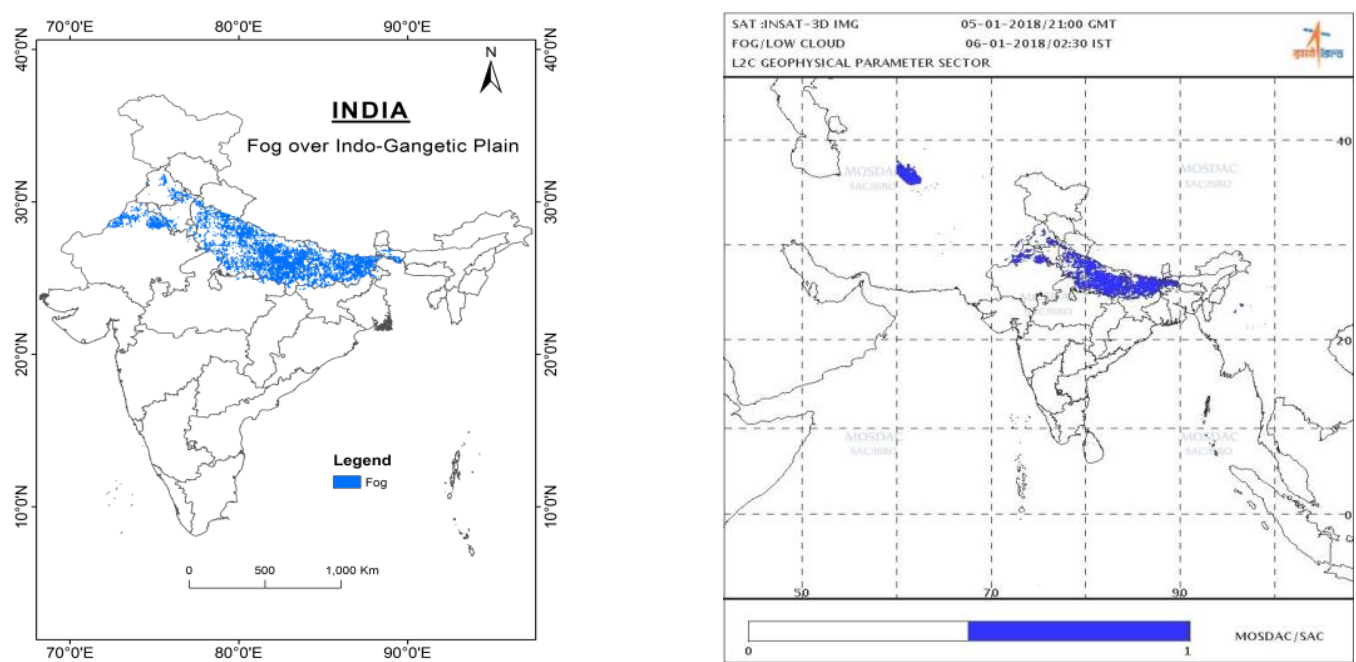

(d)

Figure 5. Fog maps and INSAT-3D imager Level-2C products for (a) 02 January 2018 (2100 UTC/0230 IST), (b) 03 January 2018 (2100 UTC/0230 IST), (c) 04 January 2018 (2100 UTC/0230 IST), and (d) 05 January 2018 (2100 UTC /0230 IST)

Following cases can be established with respect to threshold BTD from the SBDART simulation results shown in Table 3:

Case I: For optically thin fog (FOD < 4) with small fog droplet size $(\operatorname{Re}<8 \mu \mathrm{m})$, the threshold BTD for fog detection is $\sim 4 \mathrm{~K}$.

Case II: For optically thin fog (FOD < 4) with large fog droplet size $(\operatorname{Re}>10 \mu \mathrm{m})$, the threshold BTD to detect night time fog can be as low as $1.5 \mathrm{~K}$. The fog droplet size above $10 \mu \mathrm{m}$ comes under the category of dense fog.

Case III: For optically dense fog (FOD > 12) with small fog droplet size $(\operatorname{Re}<8 \mu \mathrm{m})$, the threshold BTD for fog detection is on the higher side (>5 K). This is the case of our study region, the Indo-Gangetic plain

\subsection{Threshold BTD from INSAT-3D satellite data}

Based on the different cases established using SBDART model simulations to determine threshold BTD, same thresholds were applied over INSAT-3D satellite image for the study region. Figure 5 shows the fog maps generated by applying the threshold BTD > $5 \mathrm{~K}$ to study the fog episode of first week of January 2018 ( $2^{\text {nd }}$ to $5^{\text {th }}$ January) and the corresponding INSAT$3 \mathrm{D}$ imager Level-2C product for these dates. Comparing the threshold BTD obtained from satellite image, the nature of fog over IGP during winter season can be determined, i.e. dense fog with large fog optical depth and small fog droplet size. The generated fog maps were compared with the actual INSAT-3D imager Level-2C fog product. It can be observed from the figure 5 that for threshold BTD > $5 \mathrm{~K}$, night time fog over IGP was detected with reasonable accuracy.

\section{CONCLUSION}

Using RTM simulations, spectral sensitivity analysis for two spectral channels - TIR $(10.8 \mu \mathrm{m})$ and MIR $(3.9 \mu \mathrm{m})$ has been carried out to determine a threshold BTD for night time fog detection. From the simulation results, it can be inferred that a fixed BTD threshold cannot be set to detect night time fog anywhere across the world. It will depend on different fog microphysical properties which are based on fog formation conditions for different geographical locations. For small fog droplet size, the BTD between the two channels was found on a higher side which decreases rapidly as the droplet size increases. It was also observed that the BTD between the two channels was high for optically dense fog and very low for 
optically thin fog. As per simulation results, 3 different cases had been formulated to determine threshold BTD. The BTD threshold obtained from RTM simulation results were applied to the INSAT-3D satellite image to study the fog episodes over IGP during the first week of January 2018 , i.e. $2^{\text {nd }}$ to $5^{\text {th }}$ January 2018. For the BTD > $5 \mathrm{~K}$, fog was detected for the study area with reasonable accuracy implying that the nature of fog in the Indo-Gangetic Plain comes under Case III (dense fog with large optical depth and small fog droplet size).

\section{ACKNOWLEDGEMENTS}

The authors are grateful to Director IIRS, Dean IIRS and Group Head MASD for their constant encouragement and support. The authors would like to thank Meteorological and Oceanographic Satellite Data Archival Centre (MOSDAC) and Space Applications Centre (SAC), ISRO for providing the INSAT-3D imager products.

\section{REFERENCES}

Ahmed, R., Dey, S., \& Mohan, M. (2015). A study to improve night time fog detection in the Indo-Gangetic Basin using satellite data and to investigate the connection to aerosols. Meteorological Applications, 22(4), 689-693. https://doi.org/10.1002/met.1468

Badarinath, K. V. S., Latha, K. M., Chand, T. R. K., Reddy, R. R., Gopal, K. R., Reddy, L. S. S., Narasimuhulu, K., Kumar, K. R. (2007). Black carbon aerosols and gaseous pollutants in an urban area in North India during a fog period. Atmospheric Research, 85(2), 209-216. https://doi.org/10.1016/j.atmosres.2006.12.007

Bendix, J. (2002). A satellite-based climatology of fog and lowlevel stratus in Germany and adjacent areas. Atmospheric Research, 64(1-4), 3-18. https://doi.org/10.1016/S01698095(02)00075-3

Chaurasia, S., Sathiyamoorthy, V., Paul Shukla, B., Simon, B., Joshi, P. C., \& Pal, P. K. (2011). Night time fog detection using MODIS data over Northern India. Meteorological Applications, 18(4), 483-494. https://doi.org/10.1002/met.248

Choudhury, S., Rajpal, H., Saraf, A. K., \& Panda, S. (2007). Mapping and forecasting of North Indian winter fog: An application of spatial technologies. International Journal of Remote Sensing, 28(16), 3649-3663. https://doi.org/10.1080/01431160600993470

Ellrod, G. P. (1995). Advances in the Detection and Analysis of Fog at Night Using GOES Multispectral Infrared Imagery. Weather and Forecasting, 10(3), 606-619. https://doi.org/10.1175/1520-

0434(1995)010<0606:AITDAA>2.0.CO;2

Kidder, S. Q., \& Wu, H.-T. (1984). Dramatic Contrast between Low Clouds and Snow Cover in Daytime 3.7 Imagery. Monthly Weather Review. https://doi.org/10.1175/15200493(1984)112<2345:DCBLCA>2.0.CO;2

Lee, J. R., Chung, C. Y., \& Ou, M. L. (2011). Fog detection using geostationary satellite data: Temporally continuous algorithm. Asia-Pacific Journal of Atmospheric Sciences, 47(2), 113-122. https://doi.org/10.1007/s13143-011-0002-2
Lu, C., \& Shengjie, N. (2009). Study on microphysical characteristics of winter fog in nanjing area, China. In 2008 International Workshop on Education Technology and Training and 2008 International Workshop on Geoscience and Remote Sensing, ETT and GRS 2008 (Vol. 1, pp. 273-276). https://doi.org/10.1109/ETTandGRS.2008.55

Ricchiazzi, P., Yang, S., Gautier, C., \& Sowle, D. (1983). SBDART: A Research and Teaching Software Tool for PlaneParallel Radiative Transfer in the Earth' s Atmosphere. Bulletin of the American Meteorological Society, 2101-2114. https://doi.org/10.1175/15200477(1998)079<2101:SARATS >2.0.CO;2

Srivastsava, S. K., Sharma, A. R., Sachdeva, K. (2016). Spatial and Temporal Variability of Fog Over the Indo-Gangetic Plains, India. 10(11):1042-57 